\title{
Effect of gamma radiation and accelerated aging on the mechanical and thermal behavior of HDPE/HA nano-composites for bone tissue regeneration
}

\author{
Othman Y Alothman ${ }^{1}$, Fahad N Almajhdi ${ }^{2}$ and $\mathrm{H} \mathrm{Fouad}^{3^{*}}$
}

\footnotetext{
* Correspondence: menhfefnew@ hotmail.com

${ }^{3}$ Biomedical Engineering Department, Helwan University, Faculty of Engineering, Helwan, Egypt

Full list of author information is available at the end of the article
}

\begin{abstract}
Background: The replacement of hard tissues demands biocompatible and sometimes bioactive materials with properties similar to those of bone. Nano-composites made of biocompatible polymers and bioactive inorganic nano particles such as HDPE/HA have attracted attention as permanent bone substitutes due to their excellent mechanical properties and biocompatibility.
\end{abstract}

Method: The HDPE/HA nano-composite is prepared using melt blending at different HA loading ratios. For evaluation of the degradation by radiation, gamma rays of $35 \mathrm{kGy}$, and $70 \mathrm{kGy}$ were used to irradiate the samples at room temperature in vacuum. The effects of accelerated ageing after gamma irradiation on morphological, mechanical and thermal properties of HDPE/HA nano-composites were measured.

Results: In Vitro test results showed that the HDPE and all HDPE/HA nano-composites do not exhibit any cytotoxicity to WISH cell line. The results also indicated that the tensile properties of HDPE/HA nano-composite increased with increasing the HA content except fracture strain decreased. The dynamic mechanical analysis (DMA) results showed that the storage and loss moduli increased with increasing the HA ratio and the testing frequency. Finally, it is remarked that all properties of HDPE/HA is dependent on the irradiation dose and accelerated aging.

Conclusion: Based on the experimental results, it is found that the addition of $10 \%$, 20\% and 30\% HA increases the HDPE stiffness by 23\%, 44 and 59\% respectively. At the same time, the $\mathrm{G}^{\prime}$ increased from 2.25E11 MPa for neat HDPE to 4.7E11 MPa when $30 \%$ HA was added to the polymer matrix. Also, significant improvements in these properties have been observed due to irradiation. Finally, the overall properties of HDPE and its nano-composite properties significantly decreased due to aging and should be taken into consideration in the design of bone substitutes. It is attributed that the developed HDPE/HA nano-composites could be a good alternative material for bone tissue regeneration due to their acceptable properties.

Keywords: HDPE, HA, Nano-composite, DSC, DMA, Mechanical, Accelerated aging, Gamma radiation 


\section{Introduction}

Bone is one of the most commonly replaced tissues in the human body. Native bone tissues mainly consist of nonstoichiometric hydroxyapatite $\left(\mathrm{HA} ; \mathrm{Ca}_{10}\left(\mathrm{PO}_{4}\right) 6(\mathrm{OH})_{2}\right)$ and collagen fiber matrix that provide physical and biological properties and mechanical support and protection from the vertebrate skeleton [1]. The growing demand for bone tissues replacement is due to the dramatic increase in patients suffering from bone cancer, traffic accidents and sport injuries. It is estimated that 4 millions operations carried out worldwide annually related to bone grafting or bone substitutes [2]. Currently, synthetic and natural origin materials such as metals, ceramics and polymers have been used for bone tissue engineering. Many studies have been carried out for developing different materials for bone tissue engineering such as metals, ceramics and polymers [1-5]. The metallic implants found some drawbacks such as high stress shielding and low corrosion resistance. The stress shielding is induced because the metallic bone substitute stiffness is far greater than the surrounding bone tissue. As a result, the surrounding bone tissues are insufficiently loaded compared to the metallic bone substitute leading to reduction in bone density [6,7]. The replacement of hard tissues demands biocompatible and sometimes bioactive materials with properties similar to those of bone. Nano-composites made of biocompatible polymers and bioactive inorganic nano particles have attracted attention as bone regeneration materials and even permanent bone substitutes due to their excellent mechanical properties and biocompatibility $[8,9]$.

Composites that consisting of a polymeric matrix and bioactive micro/nano particles can provide new biomaterials for bone substitutes with acceptable mechanical and bioactive properties. The developed composite properties can be tailored for a given medical use according to the particles size and ratio. Several researchers reported work on developing HA/polymer based composites material for bone replacement [10-15]. Bonfield et al. introduced the bone-analogue concept by processing composite composed of a ductile polymer matrix (Polyethylene, PE) and stiff ceramic (HA) [10]. The mechanical coupling of the reinforcement and the matrix is resulting from the shrinkage of High density polyethylene (HDPE) matrix and HA particles during the composite processing [16]. The properties of HDPE/HA composite have been extensively studied by researchers $[1,8,12,17,18]$. The specific requirement for ideal materials for bone tissue regeneration is good mechanical properties, biocompatibility, and controlled resorbability [1]. There are two crucial factors play important role in producing HDPE/HA composites with bonelike properties. The first is good interfacial adhesion between organic polymers and inorganic HA. The second is the uniform dispersion of HA in the HDPE matrix. Kinga et al. [15] developed nano HA particles that have high surface area and fabricate HDPE/HA nano composite with superior mechanical properties similar to the mineral found in human hard tissues.

It is well known that HDPE/HA bone substitute has usually been irradiated for sterilization before implantation. The sterilization process promotes cross linking and changes the properties of the composite as a short term effect. On the other hand, the sterilization has negative effects on the enlargement density of long molecular chains as well as concentration of the tie molecules as a long term effect $[19,20]$. Also, it is well known that most of polymeric materials have a viscoelastic behavior even under normal loading conditions. Their overall mechanical properties change over time due to aging 
either on shelf or in vivo. Smolko and Romero [21] studied the effects of gamma irradiation dose on the properties of different types of polymeric matrix composites for application in hard-tissue replacement. The results indicated that the modulus of elasticity in tension and tensile strength increased with increasing the radiation dose while the fracture strain decreased. Albano et al. [22] studied the effect of gamma irradiation on properties of HDPE/HA composites prepared by solution. Results indicated strong increase in MFI with radiation dose while remarkable decrease in the crystallinity and melting temperature of HDPE/HA composites. Jin-Long et al. [23] studied the effects of HA percentage on the wear and mechanical behavior of ultra high molecular weight polyethylene (UHMWPE)/HA composites and results display enhancement in hardness, modulus and wear behavior of the composite with addition of HA. Fouad et al. [24] reported that viscoelastic, thermal, rheological, hardness, wear resistance properties, and fracture behavior of HDPE/HA composites changed due to accelerated thermal ageing.

It's clear from literature review that little studies have investigated the effects of (accelerated or natural) aging after gamma irradiation on the behavior of HDPE/HA nano composites for biomedical applications. Therefore, the main objective of this part of study is to analyze the effects of different loading of nano HA particles, radiation and aging after radiation on the mechanical, thermal, visco-elastic and bioactivity behavior of the HDPE nano-composites and its application for bone tissue engineering.

\section{Materials and methods}

\section{Materials}

HDPE (melt index of $30 \mathrm{~g} / 10 \mathrm{~min}$; density of $0.954 \mathrm{~g} / \mathrm{cm}^{3}$; and average molecular weight of $800000 \mathrm{~g} / \mathrm{mol}$ ) that procured by local Saudi manufacturer is used in the present study. It is an injection molding grade of HDPE copolymer with a narrow molecular weight distribution and high flow-ability. Spray dried synthetic HA nano particles with high purity and high surface area supplied by Fluidinova, Engenharia de Fluidos, SA, Portugal were used as reinforcement for HDPE matrix. The typical size of HA nano particle is less than $100 \mathrm{~nm}$ and the average aggregate size is $2.5 \mu \mathrm{m}$.

\section{Compounding}

HDPE was premixed with different ratios of HA nano particles master-batch. The HA nano particles master-batch ratio was varied from 0 to $30 \%$. Subsequently, the pre-mix was pelletized using an intermeshing and co-rotating twin screw extruder (Farrell FTX20) [24]. The granules were further dried and conditioned in the lab environment for 40 hours. The granules were then injection molded to get a set of standard ASTM D638 type-I specimens [25]. An injection molding machine (Asian Plastic Machinery, Double Toggle IM Machine, Super Master Series SM 120) was used to prepare ASTM standard samples. Although the standard recommends testing of at least five specimens, the ASTM standard allows for testing fewer specimens if so mentioned in the report. In the present study all the experimental tests were performed using three specimens. All the results presented here are the median of the three measurements. 


\section{Gamma irradiation and aging procedures}

The nano-composite specimens were exposed to gamma irradiation at doses of 0,35 and $70 \mathrm{kGy}$ at rate of $5 \mathrm{kGy} / \mathrm{hr}$ at room temperature in vacuum. The thermally accelerated aging of irradiated and non-irradiated HDPE/HA nano-composites were performed in saline solution at temperature of $80^{\circ} \mathrm{C}$ for 4 weeks that equals to 5 years of natural aging $[24,26]$. The aging procedure used in the present study is assumed to be resulted in an aging mechanism comparable to the real in vivo aging mechanism.

\section{Scanning electron microscopy (SEM)}

The cryo-fracture surface of HDPE/HA nano-composites were examined using scanning electron microscope (SEM Model ISM 6360A, Jeol Company, Japan). The composite specimens are fixed with double coated carbon tape and surfaces of the samples were coated with a thin layer of gold under vacuum prior to the SEM observation to avoid electrostatic charging and heat build-up during observation.

\section{Cytotoxicity test}

In vitro cytotoxicity tests were performed for HDPE and HDPE/HA composite specimens using the human amnion epithelium cell line known as Wistar Institute Susan Hayflick (WISH) cells monolayer [27]. The specimens were first sterilized in order to remove other microorganisms. Sterilization was carried out using gamma irradiation at doses of $70 \mathrm{kGy}$ at rate of $5 \mathrm{kGy} / \mathrm{hr}$ at room temperature in vacuum. Each material was mixed with $10 \mathrm{ml}$ RPMI medium supplemented with $10 \%$ fetal bovine serum, $1 \%$ MEM vitamins, $2 \mathrm{mM}$ L-glutamine, $1000 \mathrm{U}$ penicillin, $1 \mathrm{mg}$ streptomycin and $2.5 \mu \mathrm{g}$ amphotericin-B was added to WISH cells monolayer for cytotoxicity evaluation. A separate flask of no HDPE specimen was used as control. All cultures were incubated at $37^{\circ} \mathrm{C} \pm 1^{\circ} \mathrm{C}$ for 5 days and examined daily for any signs of cytotoxicity (cell degeneration, lysis and detachment) using an optical microscope.

\section{Tensile properties}

The tensile properties of HDPE/HA composites were evaluated by using universal testing machine. The tensile tests up to fracture were performed at room temperature at speed of $5 \mathrm{~mm} / \mathrm{min}$. The output results were recorded as the applied load against elongation. At least three specimens were tested at each condition and the standard deviations are determined for all measured properties. The engineering yield strength was determined from the upper stress point, and Young's modulus was calculated from the initial linear region of the stress-strain data.

\section{Differential scanning calorimetry (DSC)}

Differential Scanning Calorimetry (DSC) tests of irradiated and non-irradiated HDPE and HDPE/HA nano-composites were performed on DSC-6 series (Schimadzu, Japan) with samples of $\approx 5 \mathrm{mg}$ sealed in an aluminum pan. Each specimen was placed in the DSC oven and heated from $30^{\circ} \mathrm{C} / \mathrm{min}$ to $200^{\circ} \mathrm{C}$ at rate of $5^{\circ} \mathrm{C} / \mathrm{min}$, then cooled down to $30^{\circ} \mathrm{C}$ at a cooling rate of $5^{\circ} \mathrm{C} / \mathrm{min}$. The heat of melting in each step was calculated by integrating the area under the DSC endothermic peak of the DSC thermogram. The melting temperatures of the samples were taken at the peaks of the melting processes. 
The percentage crystallinity was calculated by normalizing the heat of melting to that of $100 \%$ crystalline PE $(290 \mathrm{~J} / \mathrm{g})$ [28-31].

\section{Dynamic mechanical analysis (DMA)}

The visco-elastic properties of irradiated and non-irradiated HDPE and HDPE/HA nano-composite were characterized using a dynamic mechanical Analyzer (AR-G2 from TA, USA). The visco-elastic properties were measured under torsional arrangement. The samples were heated up to $80^{\circ} \mathrm{C}$, stabilized at this temperature for 5 minutes, and then a frequency sweep test was performed. The frequency sweep was performed from 0.1 to $500 \mathrm{rad} / \mathrm{sec}$.

\section{Results and discussions}

\section{Morphological study}

The surface morphologies of HA powder and HDPE/HA composite specimens containing 10, 20 and $30 \mathrm{wt} \% \mathrm{HA}$ are shown in Figure 1. It's clearly indicated from SEM micrographs (Figure 1a-c) that the HA nanoparticles appear as bright spots distributed in the dark HDPE matrix. A reasonable distribution of HA particles was achieved in the HDPE/HA composites. Although, the HA particles were in the nano scale-range according to the manufacturer data but SEM micrographs display agglomeration of some nano particles to be in the micro scale range $(100 \mathrm{~nm})$. It is attributed that agglomeration of HA nano particles occurs due to the tendency of HA nano particles to decrease their contact surface with HDPE matrix. Therefore, bigger particle size of HA is clearly visible in the micrograph of HDPE/HA composite specimens.

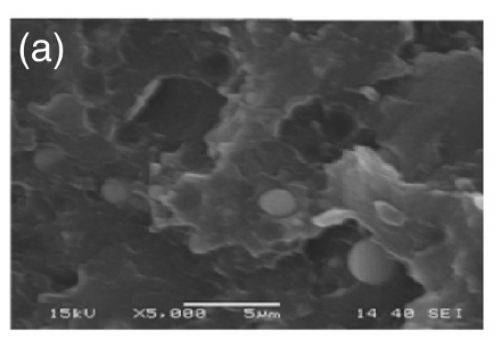

$10 \%$ HA



$30 \%$ HA

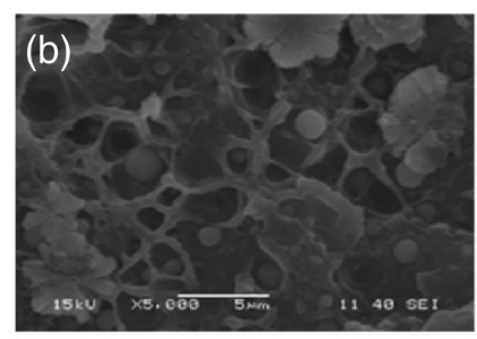

$20 \%$ HA

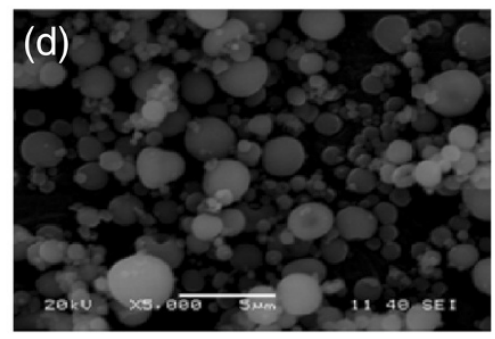

HA powder

Figure 1 SEM micrographs of HDPE/HA nano-composites and neat HA powder: (a) 10 wt $\% \mathrm{HA}$, (b) 20 wt $\%$ HA, (c) 30 wt $\%$ HA and (d) HA powder. 


\section{Cytotoxicity tests}

The in vitro cytotoxicity tests of HDPE and HDPE/HA nano-composites showed that all the cells under experimental examination remained viable and retained the features of the normal cells until the end of the experiment duration. No distinct difference was noticed between the cultures containing neat HDPE, HDPE/HA nano-composites and the control test. Signs of cell lysis and/or degeneration were completely absent as shown in Figure 2. Thus, it can be concluded that the HDPE and HDPE/HA nanocomposites do not exhibit any cytotoxicity to the WISH cell line. However, literature review reveals that experimental, histologic and clinical studies confirms the safety and efficiency of HDPE implants in aesthetic and reconstructive craniofacial surgery [30,32].

\section{Tensile properties}

The strengthening effects of HA reinforcement rely on the homogeneity of HA nano particles dispersion in the HDPE matrix. HA nano particles dispersion in the HDPE polymer matrix resulted in enhancement of the mechanical properties of HDPE/HA nano composites. The results of tensile properties showed that the Young's modulus of the neat HDPE and its nano composites are proportional to the HA content as indicated in Figures $3(a-b)$ and Table 1 . The obtained results confirmed that the HA nano particles acted as reinforcement filler by transferring the sustaining load from the matrix to the rigid particles. From Table 1, it is found that the addition of $10 \%, 20 \%$ and $30 \%$ HA increases the HDPE stiffness by $23 \%, 44$ and $59 \%$ respectively. It is believed that stiffness of HDPE/HA nano-composite increased due to the improvement of matrix stiffness and mobility restriction of polymer chains by incorporation of the HA nano-particles. Similar trends for the elastic modulus of HDPE/HA composite have been reported $[16,18]$, where the modulus increased due to the addition of HA nano-
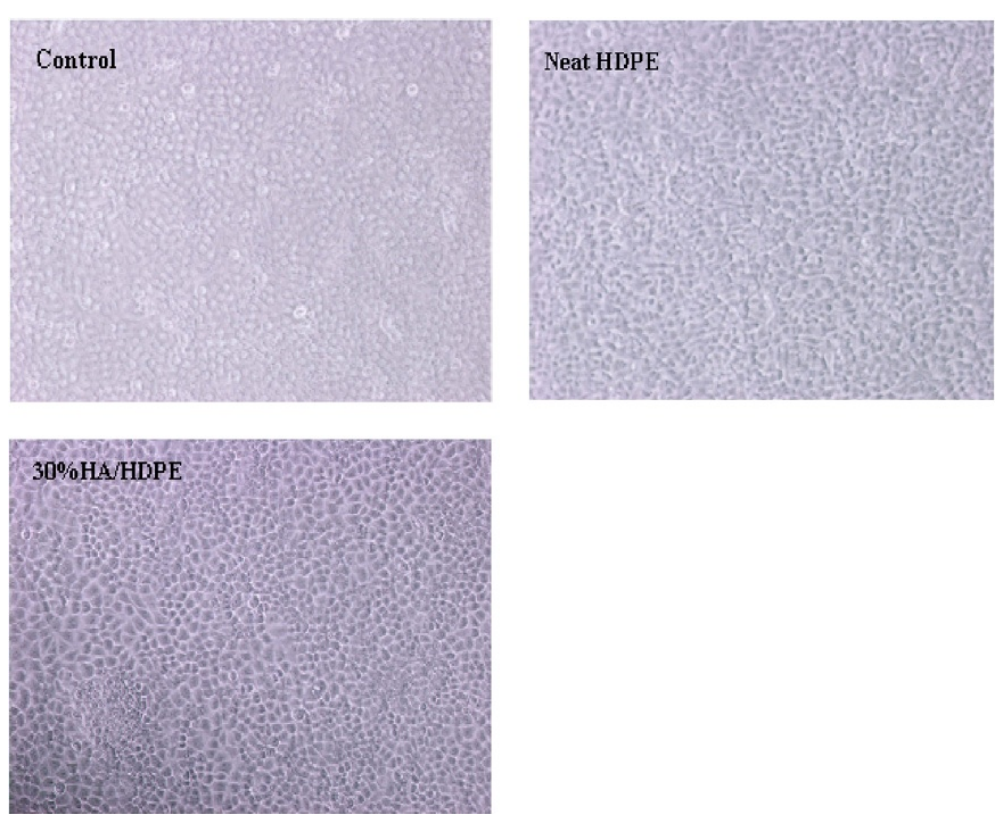

Figure 2 In vitro effect of HDPE and 30\%HA/HDPE nano-composite specimens on WISH cells after 5 days. 


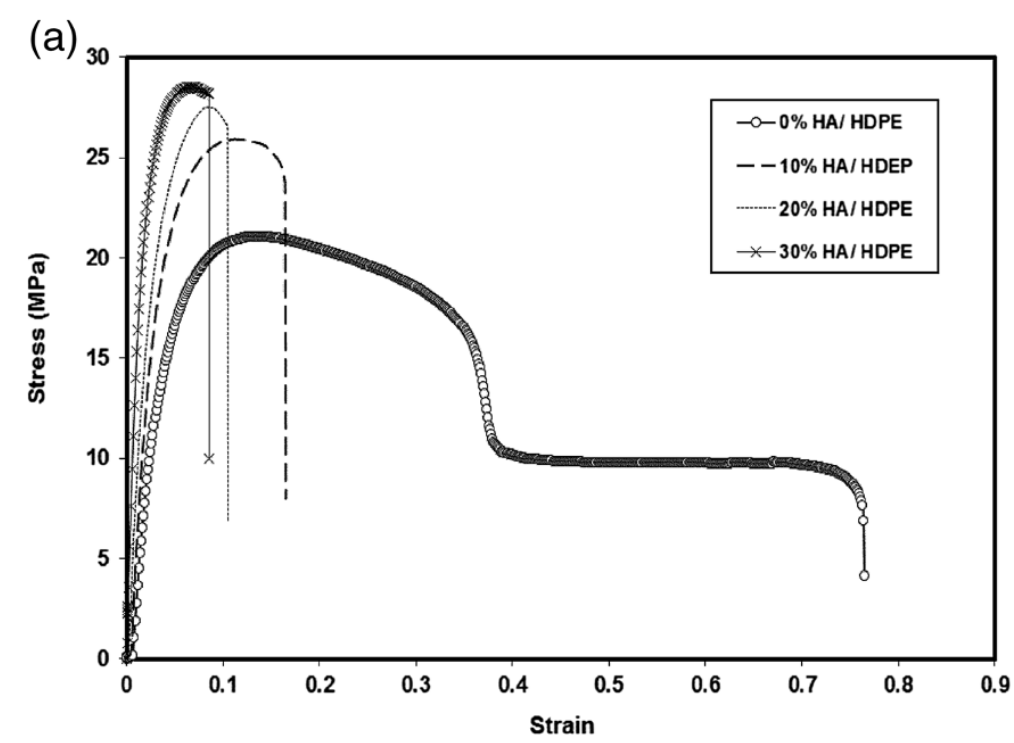

(b)

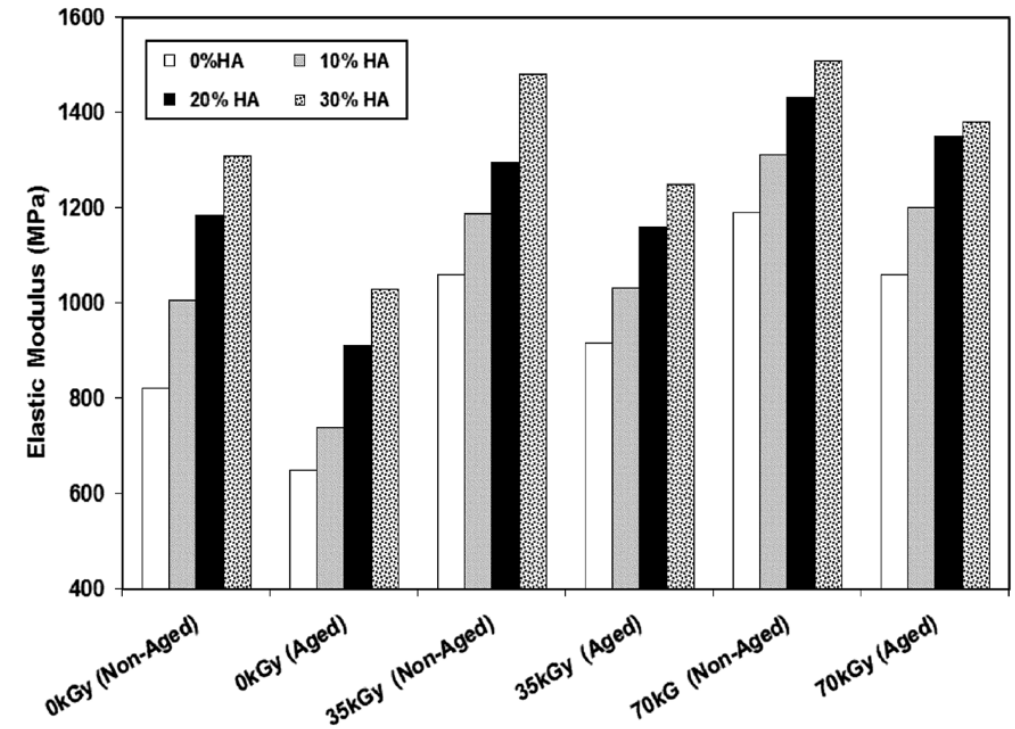

Figure 3 Effects of HA ratio on (a) Stress-strain behavior (b) Elastic Modulus of HDPE/HA nano-composites.

particles to the HDPE matrix. Figure 3(b) illustrates the Young's modulus as a function of irradiation dose and aging after irradiation of neat HA and HDPE/HA nanocomposites. Young's modulus of irradiated specimens showed remarkable increase of its value compared to non-irradiated ones due to the expected cross linking of HDPE polymer matrix that creates rigid regions that absorbed most of the applied load.

Remarkable improvement in the tensile strength is observed for HDPE/HA nano composites compared to neat HDPE (Figure 4). Ultimate strength of HDPE/HA nano composites and neat HDPE shows an improvement with irradiation dose. Previous research reported that cavitations of the polymer matrix surrounding the rigid inorganic HA nano particles can promote extensive shear yielding which resulted in improvement of mechanical properties of polymers [30,31]. In an interested work, researchers 
Table 1 Tensile properties of neat HDPE and HA/HDPE nano-composites

\begin{tabular}{|c|c|c|c|c|c|c|c|}
\hline \multirow[t]{2}{*}{ Material } & \multicolumn{4}{|c|}{ Non aged specimens } & \multicolumn{3}{|c|}{ Aged specimens } \\
\hline & $\begin{array}{l}\text { Dose } \\
\text { (kGy) }\end{array}$ & $\begin{array}{l}\text { Modulus } \\
\text { (MPa) }\end{array}$ & $\begin{array}{l}\text { Ultimate stress } \\
(\mathrm{MPa})\end{array}$ & $\begin{array}{l}\text { Fracture } \\
\text { strain }\end{array}$ & $\begin{array}{l}\text { Modulus } \\
\text { (MPa) }\end{array}$ & $\begin{array}{l}\text { Ultimate stress } \\
(\mathrm{MPa})\end{array}$ & $\begin{array}{l}\text { Fracture } \\
\text { strain }\end{array}$ \\
\hline \multirow{3}{*}{$\begin{array}{l}\text { HDPE + } \\
0 \% \text { HA }\end{array}$} & 0 & $820 \pm 36$ & $20.5 \pm 0.8$ & $76 \pm 5.8$ & $650 \pm 38$ & $18.3 \pm 0.8$ & $60 \pm 4.9$ \\
\hline & 35 & $1060 \pm 59$ & $22 \pm 1$ & $48 \pm 3.8$ & $915 \pm 55$ & $22 \pm 0.9$ & $35 \pm 3.1$ \\
\hline & 70 & $1190 \pm 88$ & $22.6 \pm 0.9$ & $26 \pm 2.1$ & $1059 \pm 52$ & $21.5 \pm 1$ & $22 \pm 1.8$ \\
\hline \multirow{3}{*}{$\begin{array}{l}\text { HDPE }+ \\
10 \% \text { HA }\end{array}$} & 0 & $1006 \pm 58$ & $25 \pm 1.4$ & $16.4 \pm 1.1$ & $740 \pm 54$ & $21 \pm 1.1$ & $13.3 \pm 1.01$ \\
\hline & 35 & $1188 \pm 79$ & $24.6 \pm 1.1$ & $13 \pm 0.92$ & $1030 \pm 60$ & $23.9 \pm 0.98$ & $11 \pm 0.87$ \\
\hline & 70 & $1310 \pm 90$ & $25.4 \pm 0.95$ & $10 \pm 0.53$ & $1200 \pm 57$ & $23.9 \pm 1.1$ & $9 \pm 0.69$ \\
\hline \multirow{3}{*}{$\begin{array}{l}\text { HDPE }+ \\
20 \% \text { HA }\end{array}$} & 0 & $1185 \pm 67$ & $27.5 \pm 1.3$ & $10.5 \pm 0.58$ & $910 \pm 60$ & $25.4 \pm 1.6$ & $9.3 \pm 0.64$ \\
\hline & 35 & $1295 \pm 70$ & $28.1 \pm 1.2$ & $9 \pm 0.72$ & $1160 \pm 63$ & $26.9 \pm 1.5$ & $7 \pm 0.48$ \\
\hline & 70 & $1430 \pm 88$ & $29 \pm 1.7$ & $8 \pm 0.53$ & $1350 \pm 80$ & $27 \pm 1.2$ & $7 \pm 0.41$ \\
\hline \multirow{3}{*}{$\begin{array}{l}\text { HDPE }+ \\
30 \% \text { HA }\end{array}$} & 0 & $1310 \pm 81$ & $28.8 \pm 1.9$ & $8.5 \pm 0.41$ & $1030 \pm 69$ & $26.3 \pm 1.5$ & $8.1 \pm 0.58$ \\
\hline & 35 & $1480 \pm 87$ & $28.9 \pm 1.5$ & $7 \pm 0.45$ & $1250 \pm 78$ & $28 \pm 1.6$ & $6 \pm 0.42$ \\
\hline & 70 & $1496 \pm 89$ & $29.1 \pm 1.5$ & $6 \pm 0.39$ & $1380 \pm 81$ & $27.5 \pm 1.3$ & $5 \pm 0.33$ \\
\hline
\end{tabular}

reported that the tensile strength of HDPE/HA composite initially decreased with the addition of HA up to 20\%, but increased for more than 30\% HA [19]. Figure 5 shows the strain at fracture of the nano composites as a function of filler contents and irradiation doses. The fracture strain showed a strong decrease due to the addition of HA nano particles and gamma irradiation. These reduction in the fracture strain can be attributed to the cross linking of polymer amorphous region. The reduction of the fracture strain due to the addition of HA nano particles could be explained by the fact that the HA leads to a restriction of molecular mobility beside acting as a crack initiator or a stress riser in the nano composite leading to composite failure at low strains $[19,30-32]$.

The accelerated aging of neat HDPE and HDPE/HA irradiated and non-irradiated nano composites resulted in remarkable changes in the behavior of the tested material. These changes are characterized by a decrease in the overall properties of the tested specimens (elastic modulus, material ductility and strength), compared with non-aged ones. The reduction in the tested materials properties due to aging can be attributed to the reduction in polymer chain segment by molecular chain session and the corresponding reduction of the tie molecules that would take place during accelerated aging [28-30]. It is important to mention that the reduction percentage in the overall mechanical properties of irradiated composite due to aging is lower than their values for non-irradiated ones. Obtained results display similar trends and agreement was observed between the present results and literature results [16-19,24,30,32].

\section{Differential scanning calorimetry (DSC)}

The thermal behavior for the first heat (melting) of HDPE and HDPE/HA nanocomposites with different HA percentage (wt\%) are shown in Table 2. The crystallization of HDPE/HA nano composites was judged via the heat of fusion $(\Delta \mathrm{H})$, where the drop in heat of fusion indicates a decrease in the crystallization. The DSC results indicated that the crystallization decreased due to the presence of HA nano 


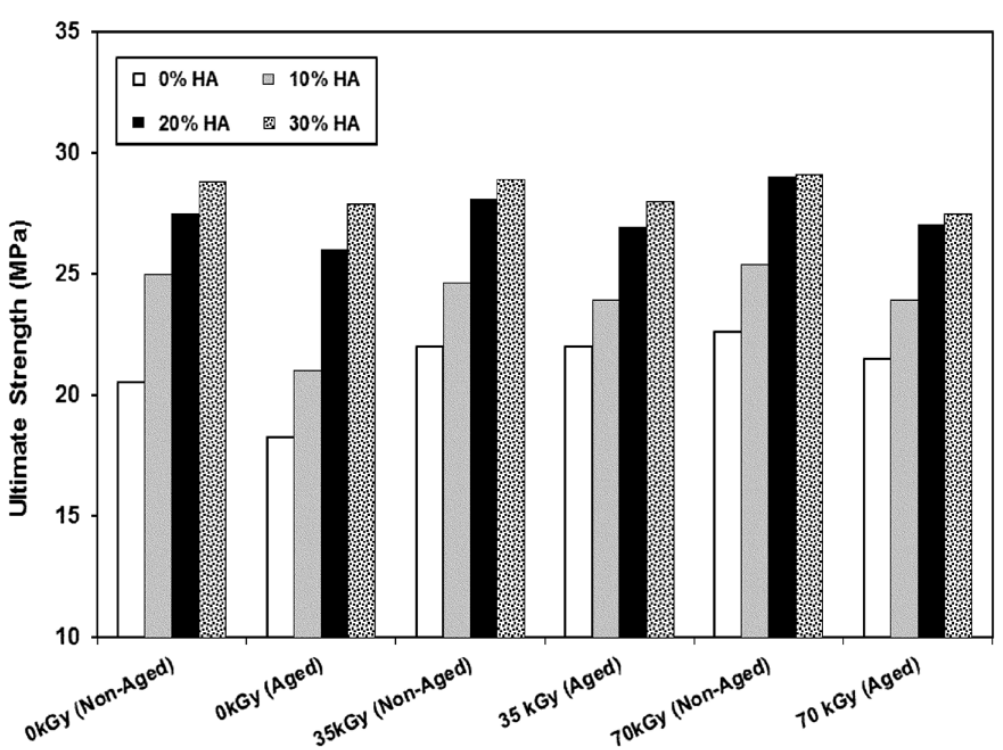

Figure 4 Variation of the ultimate strength for HDPE and HDPE/HA due to gamma irradiation and aging.

particles. From the results, it can be observed that the crystallinity of HDPE is $8 \%$ higher than that for HDPE/HA nano-composite (30\%). The main reason of such drop is the formation of conglomerates of the filler. If these conglomerates exceed the critical size, they lose their nucleating capacity. It can be also attributed to the presence of HA particles that restrict the mobility of the molecules, hence the crystallinity decreases $[30,31]$. At such high HA contents it is obvious that degree of crystallinity decreases not only due to conglomeration of fillers but also due to e.g. confinement and entanglement effects. Moreover, the effect of nanofiller on polymer crystallization is

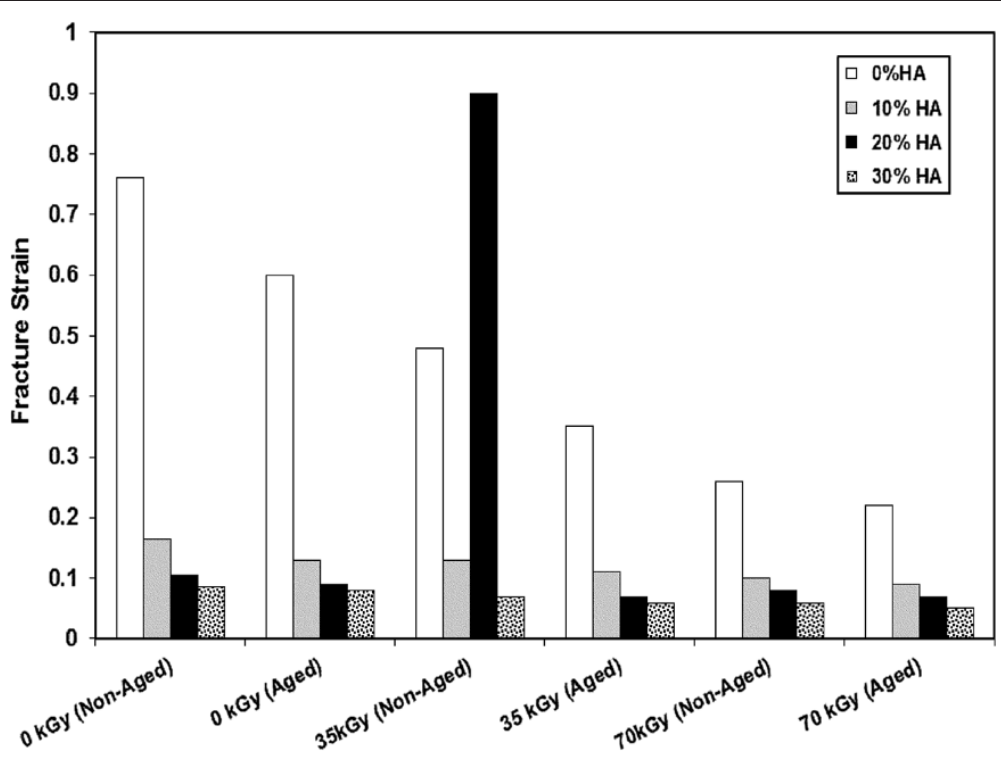

Figure 5 Variation of the fracture strain for HDPE and HDPE/HA due to gamma irradiation and aging. 
Table 2 DSC results for aged and non aged HDPE and HA/HDPE composites

\begin{tabular}{|c|c|c|c|c|c|c|c|c|c|c|c|c|}
\hline \multicolumn{7}{|c|}{ Non aged specimens } & \multicolumn{6}{|c|}{ Aged specimens } \\
\hline & $\begin{array}{l}\text { Xc\% } \\
0 \text { kGy }\end{array}$ & $\begin{array}{l}\mathrm{Tm} \\
\left({ }^{\circ} \mathrm{C}\right)\end{array}$ & $\begin{array}{c}\text { Xc\% } \\
35 \text { kGy }\end{array}$ & $\begin{array}{l}\mathrm{Tm} \\
\left({ }^{\circ} \mathrm{C}\right)\end{array}$ & $\begin{array}{c}\text { Xc\% } \\
70 \text { kGy }\end{array}$ & $\begin{array}{l}\mathrm{Tm} \\
\left({ }^{\circ} \mathrm{C}\right)\end{array}$ & $\begin{array}{l}\text { Xc\% } \\
\text { 0 kGy }\end{array}$ & $\begin{array}{l}\mathrm{Tm} \\
\left({ }^{\circ} \mathrm{C}\right)\end{array}$ & $\begin{array}{c}\text { Xc\% } \\
35 \text { kGy }\end{array}$ & $\begin{array}{l}\mathrm{Tm} \\
\left({ }^{\circ} \mathrm{C}\right)\end{array}$ & $\begin{array}{c}\text { Xc\% } \\
70 \text { kGy }\end{array}$ & $\begin{array}{l}\mathrm{Tm} \\
\left({ }^{\circ} \mathrm{C}\right)\end{array}$ \\
\hline $\begin{array}{l}\text { HDPE + } \\
0 \% \text { HA }\end{array}$ & $\begin{array}{c}54 \pm \\
1.8\end{array}$ & 134 & $60 \pm 2.1$ & 134.8 & $\begin{array}{c}63 \pm \\
1.8\end{array}$ & 135 & $59 \pm 2.2$ & 131.9 & $62 \pm 2.2$ & 132.1 & $63 \pm 2.3$ & 132.6 \\
\hline $\begin{array}{l}\text { HDPE }+ \\
10 \% \mathrm{HA}\end{array}$ & $\begin{array}{r}51 \pm \\
1.3\end{array}$ & 133 & $58 \pm 2.1$ & 133.2 & $59 \pm 2$ & 133.9 & $57 \pm 1.8$ & 131.6 & $59 \pm 2.25$ & 132.4 & $61 \pm 2.25$ & 132.8 \\
\hline $\begin{array}{l}\text { HDPE + } \\
20 \% \text { HA }\end{array}$ & $\begin{array}{r}50 \pm \\
1.31\end{array}$ & 132.3 & $54 \pm 1.66$ & 132.7 & $56 \pm 1.6$ & 133.2 & $52 \pm 1.65$ & 130.5 & $54 \pm 1.58$ & 131 & $58 \pm 1.95$ & 132 \\
\hline $\begin{array}{l}\text { HDPE + } \\
30 \% \text { HA }\end{array}$ & $44 \pm 1$ & 132.1 & $51 \pm 1.2$ & 132.5 & $53 \pm 1.5$ & 132.7 & $50 \pm 1.6$ & 130.4 & $52 \pm 1.3$ & 131.2 & $55 \pm 1.9$ & 132 \\
\hline
\end{tabular}

strongly affected by the shape and concentration of nanoparticles [33]. On the other hand, it is known that the HA filler has higher specific heat capacity that make it better heat conductor resulting in faster cooling of HDPE/HA nano-composite. This high cooling rate resulted in thin lamellar formation rather than thick crystal growth leading to lower degree of crystallinity [30,31]. The DSC results also indicated that the melting temperature is slightly changed due to aging and gamma radiation.

The results also, show that the crystallinity of HDPE and its nano-composite increases with increasing the irradiation dose as indicated in Figure 6. The crystallinity of neat HDPE and 30\% wt HDPE/HA nano-composites increases by $9 \%$ due to irradiation with $70 \mathrm{kGy}$. Such increase of crystallinity can be attributed to the cross linking of polymer chains due to gamma irradiation. The DSC results of the first heat for accelerated aged HDPE and HDPE/HA nano-composites indicated that the crystallinity of accelerated aged specimens are about 6\% higher than that of non-aged specimens for HDPE and its nano composites. These changes in the DSC results of aged HDPE and its nano composites can be attributed to the oxidation and chain scission of the tested

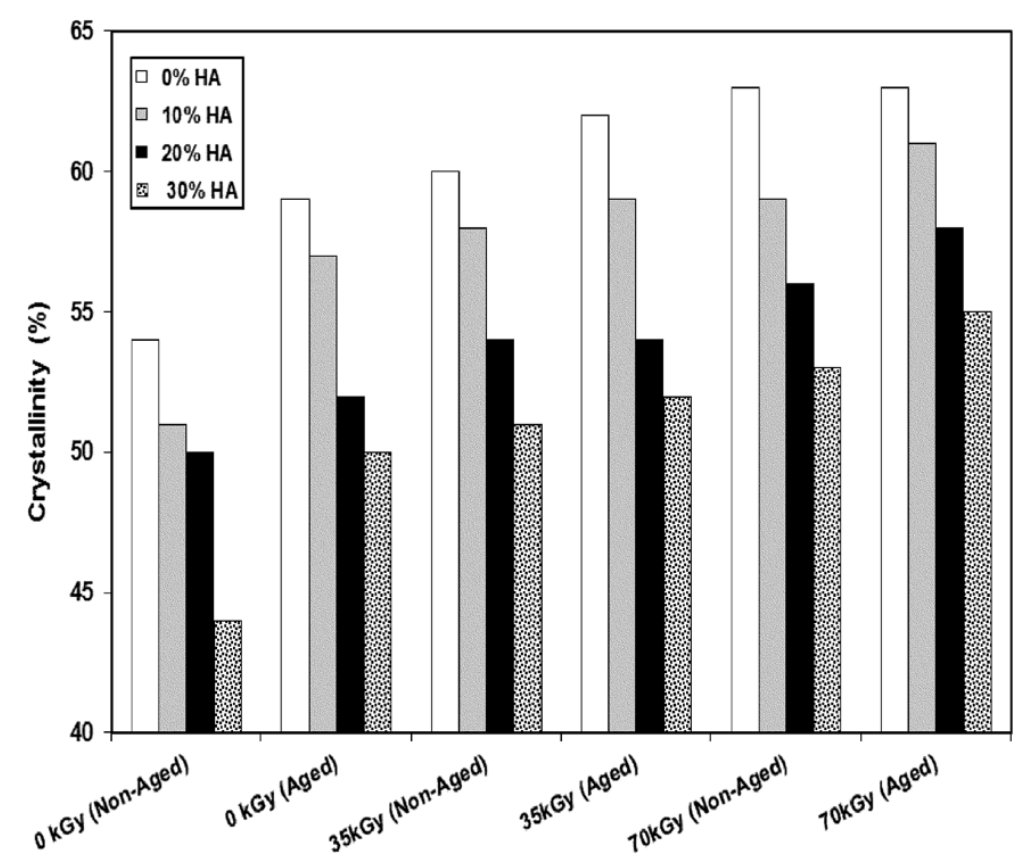

Figure 6 Variation in the crystallinity of HDPE and its composites due to irradiation and aging. 
material due to accelerated aging. The tested polymer chain scission process allows further crystal perfection and growth to occur. Therefore, the aged HDPE has higher degree of crystallinity compared to non-aged material [24,28,29].

\section{Dynamic mechanical analysis}

The response of storage modulus $\left(G^{\prime}\right)$ and Loss modulus (G') to the testing frequency for neat HDPE and HDPE/HA nano-composites at $80^{\circ} \mathrm{C}$ are illustrated in Figure 7. The inset of Figure 7 shows G' and G" for a wider range of frequency. For all tested materials, G' and G" increased with increasing the testing frequency which is a manifestation of the viscoelastic behavior of HDPE and its nano-composites. It is noticed that G' is more than G" for all materials which indicates that the elastic behavior of the material is dominant over the viscous one. It also noticed that G' and G" of all nanocomposites increased with increasing the content of HA nano particles especially at high loading frequency. For example, at $500 \mathrm{rad} / \mathrm{sec}$, the G' increased from 2.25E11 $\mathrm{MPa}$ for neat HDPE to 4.7E11MPa when 30\% HA was added to the polymer matrix. At the same testing conditions, G" for 30\% HDPE/HA nano-composite was $60 \%$ higher than that of neat HDPE. The G' and G" increase with HA content was also observed for the tensile results. This increase in the modulus of nano-composites can be attributed to the increase in the stiffness of polymeric matrix as a result of the decrease of free volume and the rise of mobility restriction due to the presence of HA nanoparticles $[30,31]$.

The effects of gamma irradiation dose on the viscoelastic properties (G' and G") of neat HDPE and 30\% HDPE/HA nano-composites as a function of testing frequency are shown in Figures 8 and 9. The results showed that the G' and G" significantly increased with increasing the irradiation dose. For example, at $500 \mathrm{rad} / \mathrm{sec}$, the G' for $30 \%$ HDPE/HA nano-composite increased by $22 \%$ and $32 \%$ due to irradiation with $35 \mathrm{kGy}$ and $70 \mathrm{kGy}$, respectively. For the G', at the same testing conditions, its value increased

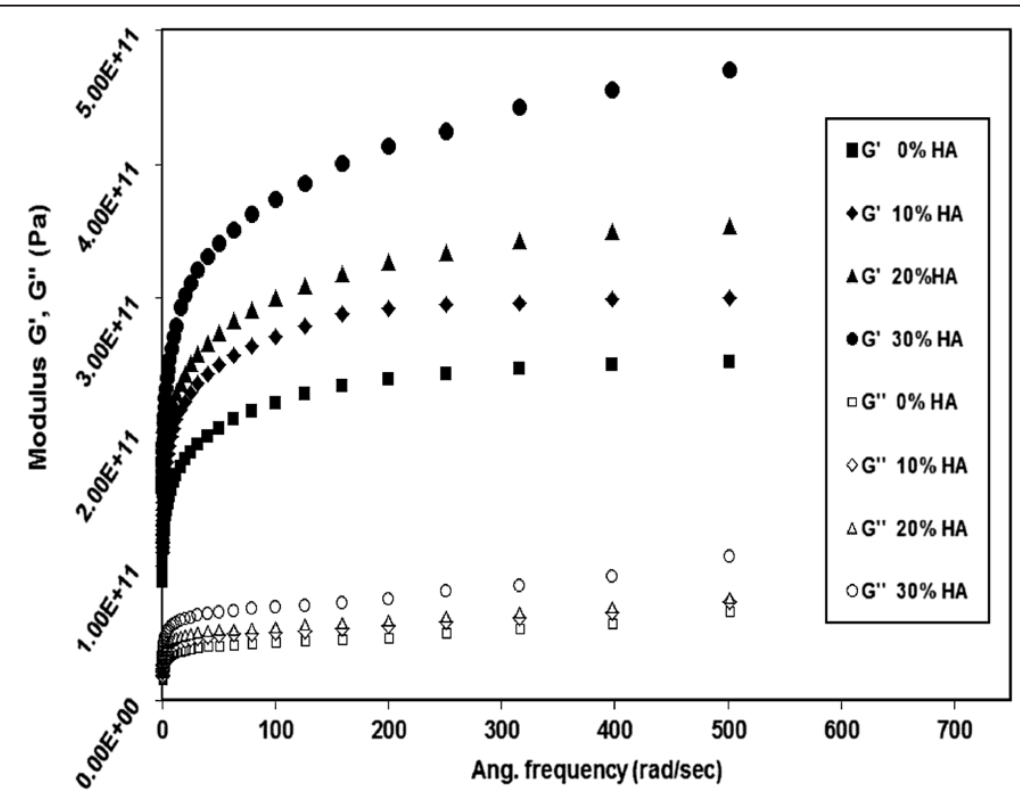

Figure 7 Variation of G' and G" with frequency for HDPE and HDPE nano composites at $80^{\circ} \mathrm{C}$. 


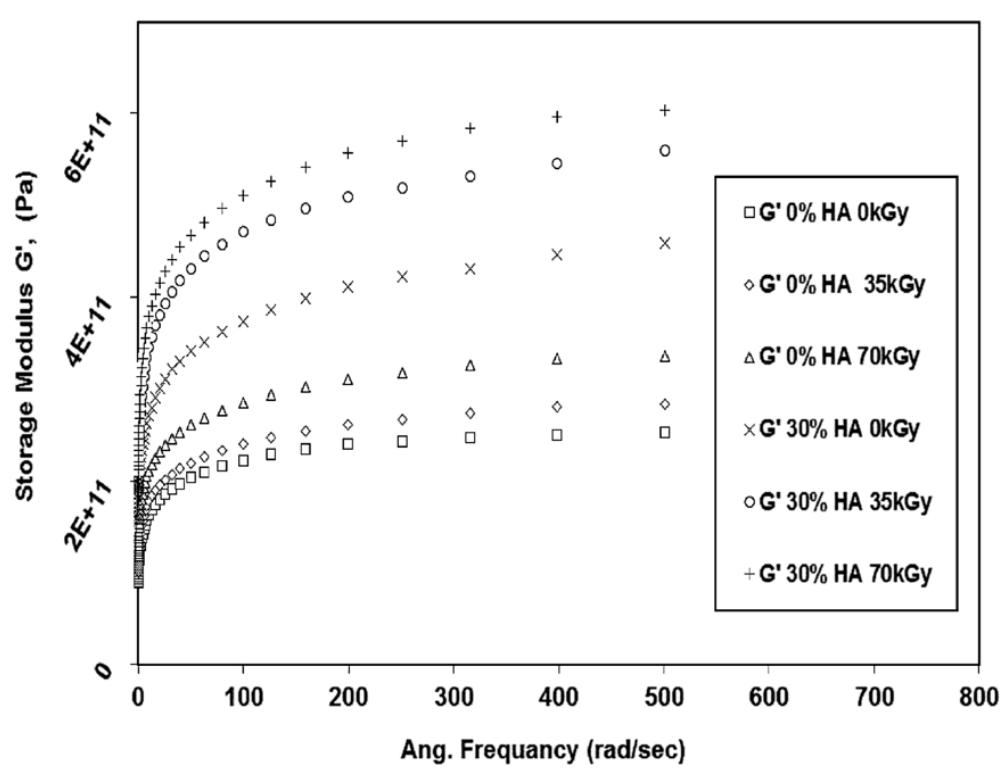

Figure 8 Variation of G' with frequency for irradiated HDPE and non-irradiated HDPE nano composites at $80^{\circ} \mathrm{C}$.

by $11 \%$ and $25 \%$ due to irradiation of 30\% HDPE/HA nano-composite with $35 \mathrm{kGy}$ and 70 kGy, respectively. Similar trends for G' and G" have been obtained for the $10 \%$ and $20 \%$ HDPE/HA nano-composites. The improvement in modulus values due to irradiation can be attributed to the cross linking of polymer chains that is occur in the amorphous region and the creation of rigid regions in the polymer matrix.

The accelerated aging of non irradiated and gamma irradiated specimens resulted in remarkable decrease in G', and G" for all testing frequencies as indicated in Figures 10 and 11. The results showed that the G' of non irradiated neat HDPE (0 kGy) decreased by $90 \%$ due to aging. This reduction in G' due to aging becomes $30 \%$ for $70 \mathrm{kGy}$ irradiated neat HDPE specimens. For 30\% HDPE/HA (0 kGy), G' decreased by $42 \%$ due to aging. For the same specimens (30\% HDPE/HA) irradiated by $70 \mathrm{kGy}$, G' dropped by

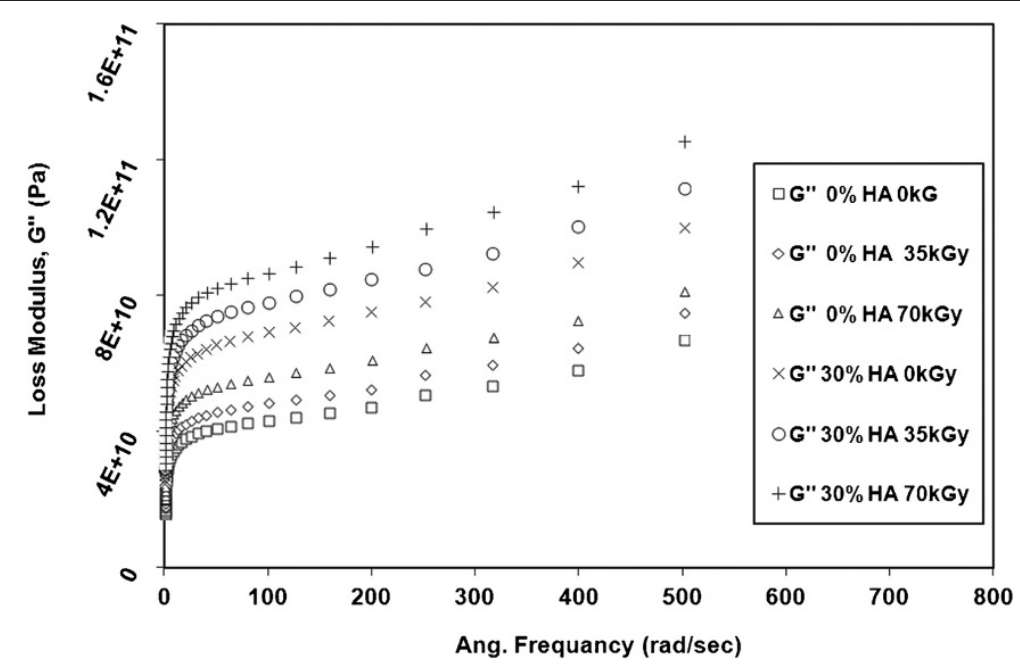

Figure 9 Variation of G" with frequency for irradiated HDPE and HDPE nano composites at $80^{\circ} \mathrm{C}$. 


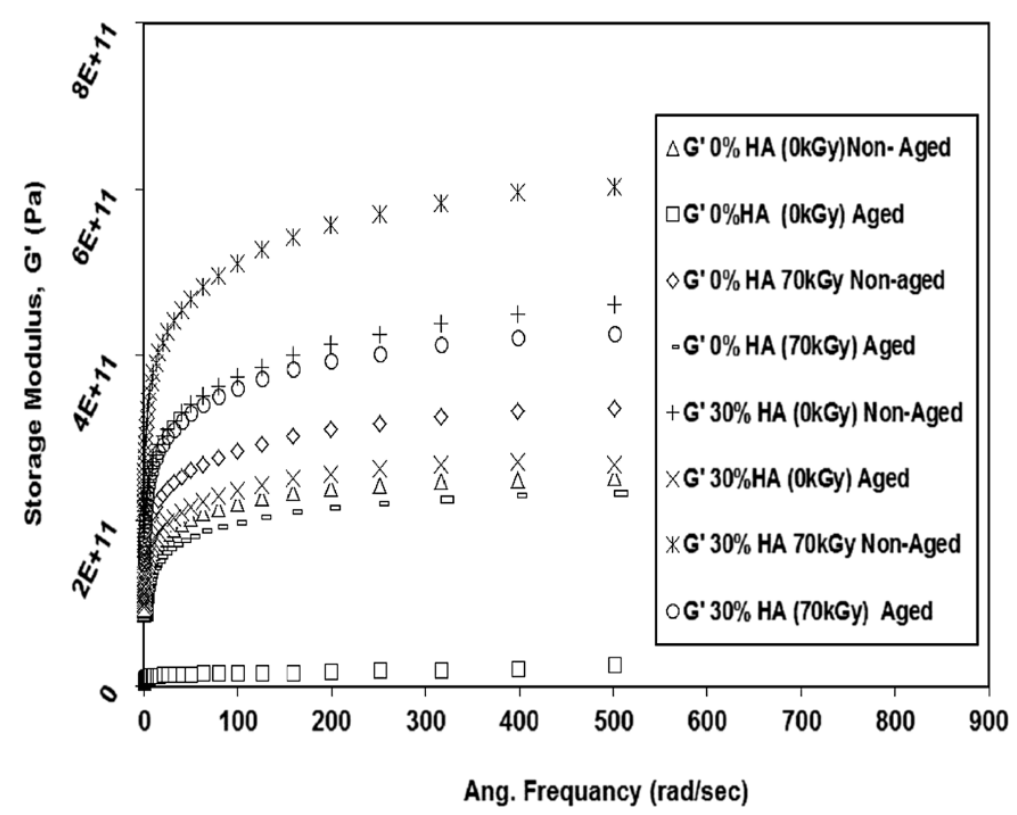

Figure 10 Effect of aging on the $G^{\prime}$ with frequency for irradiated and non-irradiated HDPE and HDPE nano composites at $80^{\circ} \mathrm{C}$.

29\%. Similar trends have been also observed for the G" where its values decreased due to aging for both irradiated and non irradiated neat HDPE and HDPE/HA nanocomposites. The reduction in the properties of aged neat HDPE specimens and its nano-composites compared to non-aged ones are attributed to the material oxidation and its corresponding chain scission. The chain scission process results in an increase of polymer crystallinity (due to lamella thickening), breakage of the polymer long chains, reduction of tie molecules, and reduction in the tested material molecular weight, increasing material brittleness, and weakening their properties [20,24,28,29].

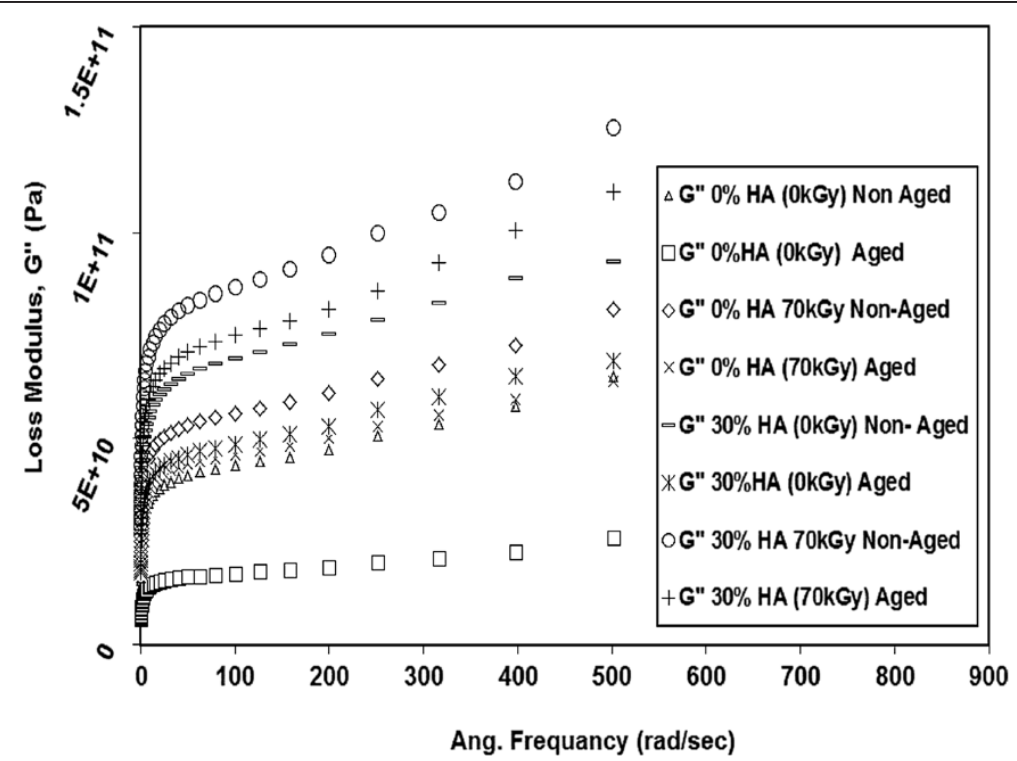

Figure 11 Effect of aging on the G" with frequency for irradiated and non-irradiated HDPE and HDPE nano composites at $80^{\circ} \mathrm{C}$. 
From the above results, it can be remarked that the reduction in the properties of nonirradiated HDPE and HDPE/HA nano-composites due to aging is higher than that for the irradiated ones. This may be attributed to that the cross linking due to irradiation is predominant than the chain scission process which occurred due to aging.

From the losses modulus (DMA) results, it can be noticed that the glass transition temperature $(\mathrm{Tg})$ ranges from $31^{\circ} \mathrm{C}$ to $33^{\circ} \mathrm{C}$ for irradiated and non-irradiated neat HDPE and HDPE/HA nano composites. According to these results, it can be concluded that there is no significant change in $\mathrm{Tg}$ due to the presence of $\mathrm{HA}$ or due to gamma irradiations. Also, it is important to mention that the values of Tg weren't clear in our DSC graphs.

\section{Conclusions}

HDPE with good distribution of HA nano particles was successfully prepared using twin screw extrusion. Neat HDPE and HDPE/HA nano-composites do not exhibit any cytotoxicity to the WISH cell line. HA nano particles decreased the crystallinity of HDPE composites due to the restriction of mobility of the molecules. Aging of HDPE/HA nano composites resulted in increase of the crystallinity due to expected oxidation and chain scission. With increasing the HA nano particles contents, the storage, loss modulus and Young's modulus of the nano-composite increased while the strain at fracture decreased proportional to the HA content. Irradiation of HDPE and HDPE/HA nano composites resulted in significant modification in their mechanical and visco-elastic behavior. Aging of HDPE/HA nano-composites resulted in decrease of the storage, loss modulus, Young's modulus and strain at fracture. The reduction in the properties of non-irradiated HDPE and HDPE/HA nano-composites is due to aging is higher than that for the irradiated ones. HDPE/HA nano-composite could be a good alternative materials for bone tissue regeneration. Finally, it is attributed that the developed HDPE/HA nano-composites could be a good alternative advanced materials for bone tissue regeneration due to their acceptable architectures and properties.

Competing interests

The authors certify that there is no actual or potential conflict of interest to declare in relation to this paper.

\section{Authors' contributions}

FNA was involved in the design of study from the biological point of view, save the biological materials as well as helped in the manuscript preparation. HF and OYA were involved in the design of study from the engineering point of view, fabrication and characterization of the composite under investigation as well as drafted the manuscript. All the authors have read and approved the final manuscript.

\section{Acknowledgements}

The authors extend their appreciation to the Deanship of Scientific Research at King Saud University for funding the work through the research group project No. RGP-VPP-133.

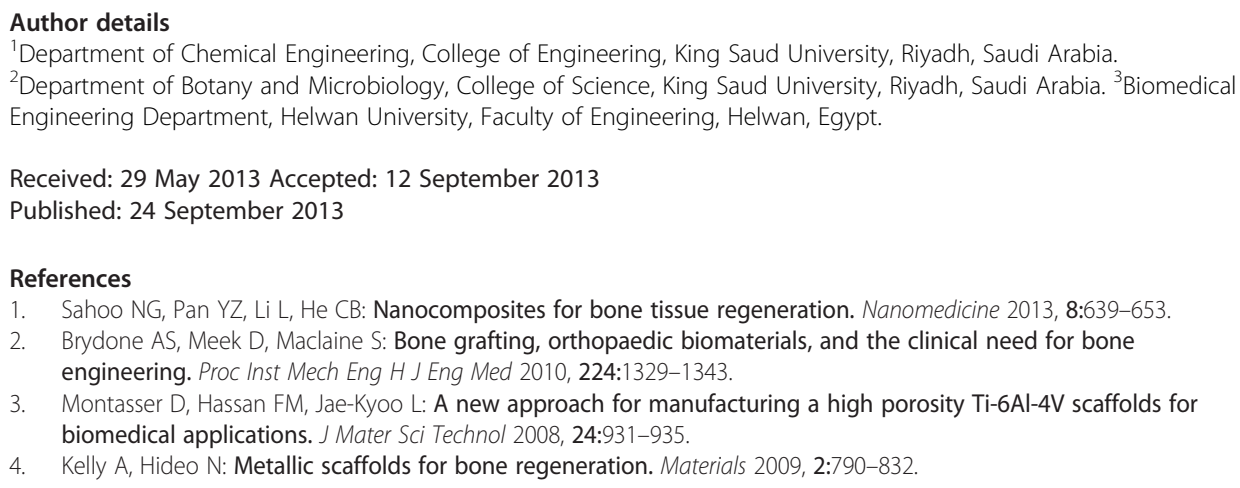


5. Rezwan K, Chen QZ, Blaker JJ, Boccaccini AR: Biodegradable and bioactive porous polymer/inorganic composite scaffolds for bone tissue engineering. Biomaterials 2006, 27:3413-3431.

6. Fouad $\mathrm{H}$ : Effects of the bone-plate material and the presence of a gap between the fractured bone and plate on the predicted stresses at the fractured bone. Med Eng Phys 2010, 32:783-789.

7. Fouad $\mathrm{H}$ : Assessment of function-graded materials as fracture fixation bone-plates under combined loading conditions using finite element modeling. Med Eng Phys 2011, 33:456-463.

8. Barone DTJ, Raquez JM, Dubois P: Bone-guided regeneration: from inert biomaterials to bioactive polymer (nano) composites. Polym Adv Technol 2011, 22:463-475.

9. Sun F, Zhou H, Lee J: Various preparation methods of highly porous hydroxyapatite/polymer nanoscale biocomposites for bone regeneration. Acta Biomater 2011, 7:3813-3828.

10. Bonfield W, Grynpas MD, Tully AE, Bowman J, Abram J: Hydroxyapatite reinforced polyethylene-a mechanically compatible implant material for bone replacement. Biomaterials 1981, 2:185-196.

11. Liming F, Yang L, Ping G: Processing of hydroxyapatite reinforced ultrahigh molecular weight polyethylene for biomedical applications. Biomaterials 2005, 26:3471-3478.

12. Albano C, Cataño L, Figuera L, Perera R, Karam A, González G, Noris K: Evaluation of a composite based on highdensity polyethylene filled with surface-treated hydroxyapatite. Polym Bull 2009, 62:45-55.

13. Sapuan SM, Mustapha F, Maijid DL, Leman Z, Ariff AHM, Ariffin MKA, Zuhri MYM, Ishak MR, Sahari J: Effect of hydroxyapatite reinforced high density polyethylene composites on mechanical and bioactivity properties. Key Eng Mater 2011, 471-472:303-308.

14. Kai L, Sie CT: Preparation and mechanical and tribological properties of high-density polyethylene/ hydroxyapatite nanocomposites. J. Macromol. Sci., Phys 2011, 50:1325-1337.

15. Pielichowska K, Blazewicz S: Bioactive polymer/hydroxyapatite (Nano)composites for bone tissue regeneration. Adv Polym Sci 2010, 232:97-207.

16. Tanner KE, Downes RN, Bonfield W: Clinical applications of hydroxyapatite reinforced materials. Br Ceram Trans 1994, 93:104-107.

17. Younesi M, Bahrololoom ME: Producing toughened PP/HA-LLDPE ternary bio-composite using a two-step blending method. Mater Des 2009, 30:4253-4259.

18. Albano C, Perera R, Cataño L, Karam A, González G: Prediction of mechanical properties of composites of HDPE/HA/EAA. J Mech Behav Biomed Mater 2011, 4:467-475.

19. Albano C, Karam A, Perera R, González G, Domínguez N, González J, Sánchez Y: HDPE/HA composites obtained in solution: effect of the gamma radiation. Nuclear Instruments and Methods in Physics Research B: Beam Interactions with Materials and Atoms 2006, 247:331-341.

20. Wannomae KK, Christensen SD, Freiberg AA, Bhattacharyya S, Harris WH, Muratoglu OK: The effect of real-time aging on the oxidation and wear of highly cross-linked UHMWPE acetabular liners. Biomaterials 2006, 27:1980-1987.

21. Smolko E, Romero G: Studies on crosslinked hydroxyapatite- polyethylene composite as a bone-analogue material. Radiat Phys Chem 2007, 76:1414-1418.

22. Albano C, Karam A, Gonzalez G, Domınguez N, Sanchez Y, Manzo F, Guzman-Garcia C: Effect of gamma irradiation on HDPE/HA (80:20) composites. Polym Adv Techno 2005, 16:283-285.

23. Jin-long L, Yuan-yuan Z, Qing-liang W, Shi-rong GE: Biotribological behavior of ultra high molecular weight polyethylene composites containing bovine bone hydroxyapatite. Journal of China University of Mining and Technology 2008, 18:606-612.

24. Fouad H, Elleithy R, Alothman OY: Thermo-mechanical, wear and fracture behavior of high-density polyethylene/hydroxyapatite nano composite for biomedical applications: effect of accelerated aging. J Mater Sci Technol 2013, 29:573-581.

25. ASTM D638-98: Standard test method for tensile properties of plastics, Vol. 08.01, 1999 annual book of ASTM standards. USA: PA; 1999

26. Premnath $\mathrm{V}$, Bellare A, Merrill EW, Jasty M, Harris WH: Molecular rearrangements in ultra high molecular weight polyethylene after irradiation and long-term storage in air. Polymer 1999, 40:2215-2229.

27. William DM, Walter LD: Fine structure and immunofluorescent studies of the WISH cell line. In Vitro Cellular and Developmental Biology: Journal of the Tissue Culture Association 1986, 22:716-724.

28. Mourad A-H I, Fouad H, Elleithy R: Impact of some environmental conditions on the tensile, creep-recovery, relaxation, melting and crystallinity behaviour of UHMWPE-GUR 410-medical grade. Mater Des 2009, 30:4112-4119.

29. Fouad H: Effect of long-term natural aging on the thermal, mechanical, and viscoelastic behavior of biomedical grade of ultra high molecular weight polyethylene. J Appl Polym Sci 2010, 118:17-24.

30. Fouad H, Elleithy R: High density polyethylene/graphite nano-composites for total hip joint replacements; processing and in vitro characterization. J Mech Behav Biomed Mater 2011, 7:1376-1383.

31. Fouad H, Elleithy R, Al-Zahrani SM, Al-haj AM: Characterization and processing of high density polyethylene/ carbon nano-composites. Mater Des 2011, 32:1974-1980.

32. Deshlpande S, Munoli A: Long-term results of high-density porous polyethylene implants in facial skeletal augmentation. An Indian perspective Indian Journal of Plastic Surgery 2010, 43:34-39.

33. Li CY: Polymer single crystal meets nanoparticles. J Polym Sci B 2009, 47:2436-2440.

doi:10.1186/1475-925X-12-95

Cite this article as: Alothman et al:: Effect of gamma radiation and accelerated aging on the mechanical and thermal behavior of HDPE/HA nano-composites for bone tissue regeneration. BioMedical Engineering OnLine 2013 12:95. 